\title{
AN EVALUATION OF THE URBAN STORM WATER RUNOFF POLLUTANT REMOVAL EFFICIENCY WITH A FOCUS ON THE RETENTION TIME
}

\author{
Vilmantè Karlavičiene \\ Vilnius Gediminas Technical University, Lithuania/Linnaeus University, Sweden \\ Raminta Rudzevičiūtè \\ Mindaugas Rimeika \\ Monika Reinikyte \\ Vilnius Gediminas Technical University, Lithuania \\ William Hogland \\ Linnaeus University, Sweden
}

\begin{abstract}
In urban areas, during heavy rain events various pollutants are flushed off impervious surfaces with storm water runoff and through the storm water drainage system directly discharged to surface water bodies. Commonly, storm water runoff sedimentation tanks are used to remove suspended solids and total petroleum hydrocarbons from the first portions of storm water runoff. Unfortunately, the operation of especially storm water sedimentation tanks is still quite complicated and not very effective. The regulation of outflow rate can be one of the ways to increase the effectiveness of pollutants removal using sedimentation tank technology. The research was performed at the storm water runoff treatment unit based on the sedimentation process. The aim of the study was to investigate the removal of suspended solids (SS) and total petroleum hydrocarbons (TPH) at the storm water runoff sedimentation tank with a focus on the retention time. Initially, the distribution of concentration of SS and TPH in various places of sedimentation tank after the rain event was investigated. The obtained results showed that the concentrations of SS and TPH are very similar all over the tank after a rain event. Therefore, it is more reasonable to take one composite sample instead several grab samples during the research of sedimentation process efficiency. According to the obtained SS and TPH removal efficiency results it was determined that optimal storm water runoff retention time in the researched sedimentation tank is 48 hour, when the inflow and outflow of sedimentation tank are closed.
\end{abstract}

\section{KEYWORDS}

Storm water runoff, sedimentation tank, suspended solids, total petroleum hydrocarbons, retention time, outflow regulation. 


\section{INTRODUCTION}

In expansive urban areas, during heavy rain events storm water runoff flush various pollutants and through the separate storm water drainage system directly discharge to surface water bodies [1]. Currently, one of the most relevant environmental problems is proper storm water runoff management in urban areas in accordance with the principles of sustainable development.

The amount of generated storm water runoff and its negative impacts (for instance, erosion holes, network damages, flooding) are increasing permanently as a consequence of the urban development resulting in expanded impervious areas.

Typical pollutants for storm water runoff are suspended solids, total petroleum hydrocarbons (especially from the streets), various trash, organic, inorganic and pathogenic contaminants and others [2].

Removal of storm water runoff pollutants is associated with storm water runoff accumulation and short-term storage in tanks (ponds), therefore the retention time is the most important criterion for the optimisation of the treatment process. Retention time is defined as the ratio between the pond volume and discharge rate [3]. Novotny says that the longer retention time ensures the more effective removal of pollutants. At the same time, the lengthening of the retention time gives better results until certain moment after which the pollutant removal efficiency is not increasing [3]. In literature it is indicated, that in order to remove SS from storm water runoff by sedimentation process the optimal retention time is $24-48$ hours [4]. The optimisation of maintenance of existing storm water runoff treatment facilities is one of crucial factors in sustainable storm water management. Integrating new storm water runoff drainage systems to the existing network appear difficulties in successful operation of storm water runoff drainage network and treatment systems. Often storm water runoff drainage systems are expanded without intermediate flow regulation tanks. Therefore it is important to know more about the operation characteristics of the earlier build facilities under overloaded conditions. Particularly obscure information exists about the sedimentation tanks which were built in Lithuania in Soviet Union time and are still in operation.

The aim of the study was to investigate the removal of SS and TPH at the storm water runoff sedimentation tank with the focus on the retention time.

\section{METHODOLOGY}

The pollutants selected for the study were suspended solids (SS) and total petroleum hydrocarbons (TPH). These pollutants are likely to be found in urban runoff from parking lots, streets, and vehicle maintenance yards.

In order to research the removal of SS and TPH, during the warm period of year 2009 totally 131 sample was taken for the determination of the concentrations of SS and TPH, the hydraulic regime of the sedimentation tank was observed, the flow rate of the inflow and outflow was estimated, also the meteorological data were collected.

\section{Site description}

As a research object, the full scale storm water runoff treatment facility situated in the district of Karoliniskes, Vilnius city, Lithuania was selected. It is situated in the west part of Vilnius city and receives the storm water runoff from the catchment area covering the districts of Pilaite, Viršuliškes, Lazdynai, Pašilaičiai and Karoliniškes. 
Totally the catchment area is approximately 342 ha and in the nearest future it is planned to direct additionally the storm water runoff from the area of 250 ha. The selected treatment facility was constructed in the 1970-s to pretreat storm water runoff removing SS and TPH

and consists of two sections, which are designed as sedimentation tanks from the equal distribution zone, sedimentation zone and discharge zone. The scheme of the storm water runoff treatment facility is shown in Figure 1.

The modification of storm water runoff outlet was done in the second sedimentation tank (II tank). In order to take storm water runoff samples from two different depths, there were installed two regulation valves $\varnothing 50 \mathrm{~mm}$ in the construction of the outlet (see Figure 2).

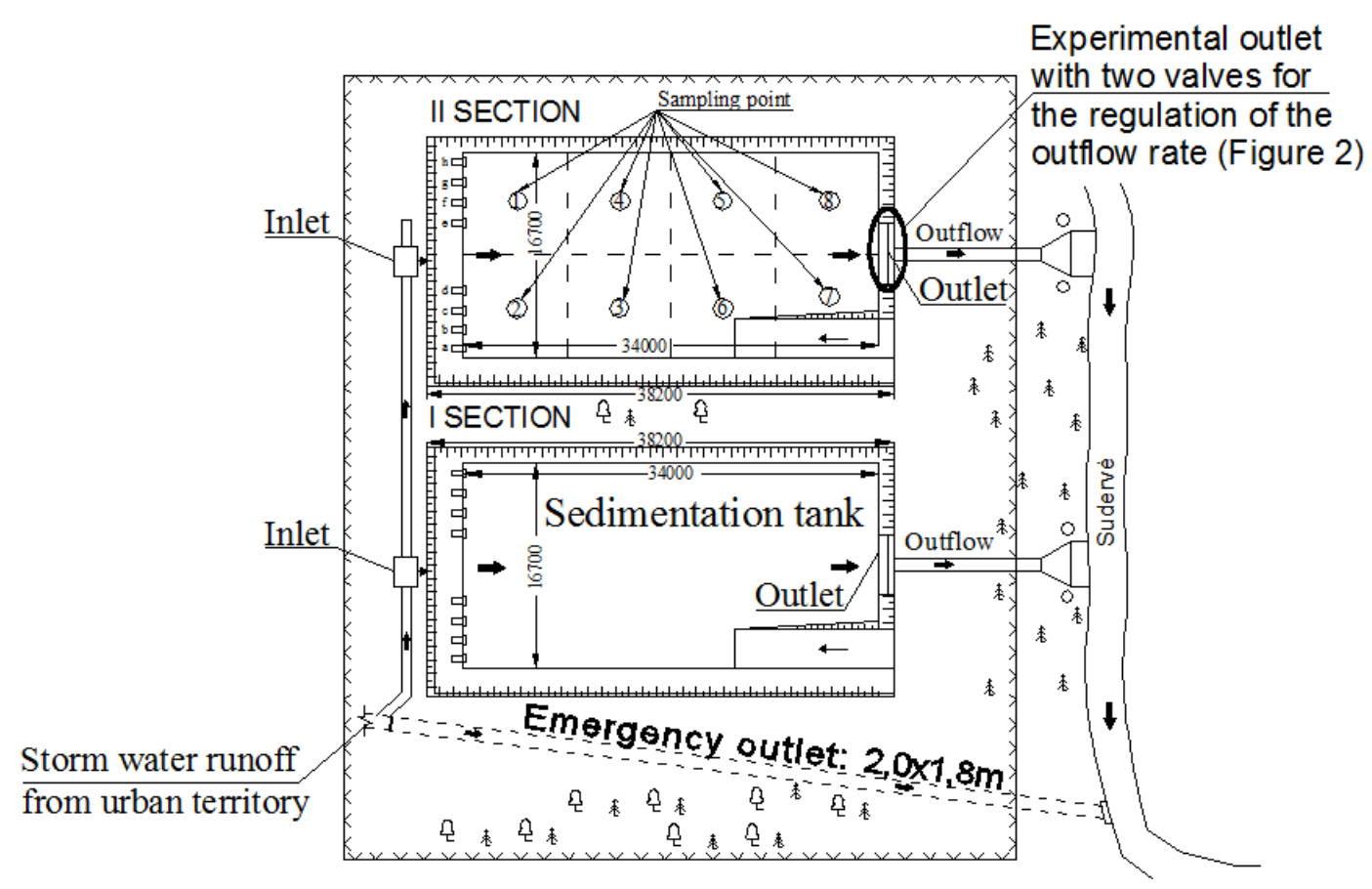

Figure 1. The scheme of the researched storm water runoff treatment facility in the catchment area of Karoliniškès district, Vilnius, Lithuania.

The height of the water level in the outlet pipe was measured and the flow rate of discharged storm water runoff was estimated [5]. 


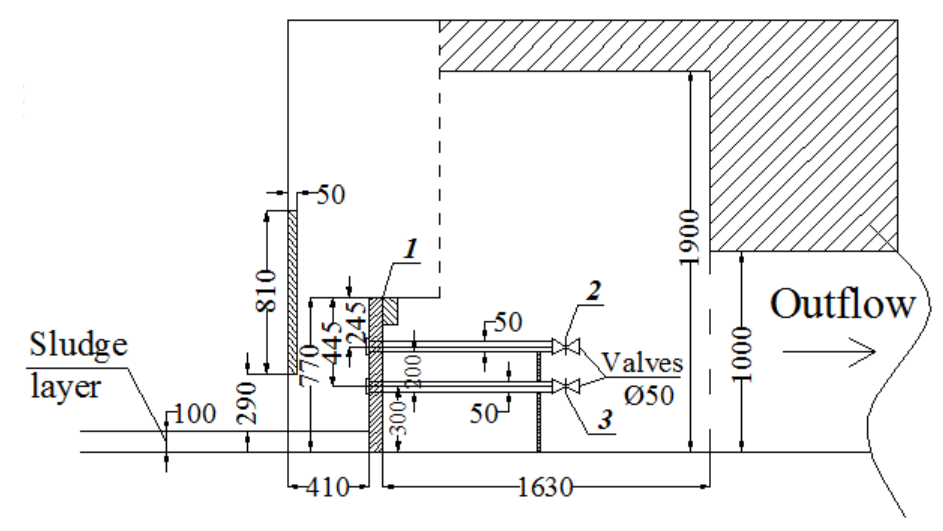

Figur 2. The construction of the experimental outlet with two valves for the regulation of the outflow rate at the storm water runoff sedimentation tank.

Under normal operation all inlet pipes are fully open, and only due to the peculiarities of construction of the inlet, the first portions of storm water runoff fall to the first section. When the storm water runoff flow rate rises, then it goes to the second section. During heavy rain events when flow rate of storm water runoff rises even more and sedimentation tanks are full, the surplus of collected storm water runoff directly is discharged to the receiving water body by emergency outlet without any treatment (Figure 1). Storm water runoff from sedimentation tanks is discharged to the small ditch named Suderve and very often, especially during summer time and heavy rain events, the discharged water is a major part of the ditch flow.

\section{SAMPLING}

\section{Calculation of the pollutant removal efficiency}

The efficiency of the removal of pollutants was calculated according the (1) formula. The initial storm water runoff pollution for the first section efficiency calculation was determined in samples taken at the inflow of the sedimentation tank after certain duration from the end of researched rain event. At the same time, the initial storm water runoff pollution for the second section efficiency calculation was determined in composite sample combined from 8 grab subsamples, taken from whole volume of accumulated storm water runoff in the second sedimentation tank (Figure 1).

$$
E_{\%}=\frac{C_{0}-C_{1}}{C_{0}} \cdot 100, \%,
$$

here: $\mathrm{C}_{0}$ - pollutant concentration in sample taken at the inlet or sedimentation tank in a short time after the rain event finished but not later than 2 hours after the rain event end, $\mathrm{mg} / \mathrm{l} ; \mathrm{C}_{1}-$ pollutant concentration at the outlet, $\mathrm{mg} / \mathrm{l}$.

Because of high variability of storm water runoff inflow rate, the concentration of SS and TPH in the second sedimentation tank and in the inflow of the first section was determined: 1) when dry weather conditions continue 2-5 days; 2) after the rain event, when the duration of rain event was not shorter than 2 hours. 
The inflow of the second section was closed, after the sedimentation tank was filled with storm water runoff and the inflow of the first section was open during the whole experiment and the drainage water was leaching all the time.

In order to determine the initial concentration of pollutant $\left(\mathrm{C}_{0}\right)$ the second sedimentation tank was sampled after five rain events: I - 16 of July, dry weather period - 3 days, duration of heavy rain event - 14 hours; II - 27 of July, dry weather period - 3 days, duration of rain event - 2 hours; III - 29 of August, dry weather period - 5 days, duration of heavy rain event - 2 hours; IV - 28 of September, dry weather period - 2 days, duration of rain event - 8 hours; V - 7 of October, dry weather period - 2 days, duration of rain event- 5 hours. During each sampling 81,5 litre volume grab samples were taken from sampling sites shown in the figure1. All samples were taken from the depth of $0,45 \mathrm{~m}$ with the bathometer (Figure 3 ) made in the laboratory of VGTU.

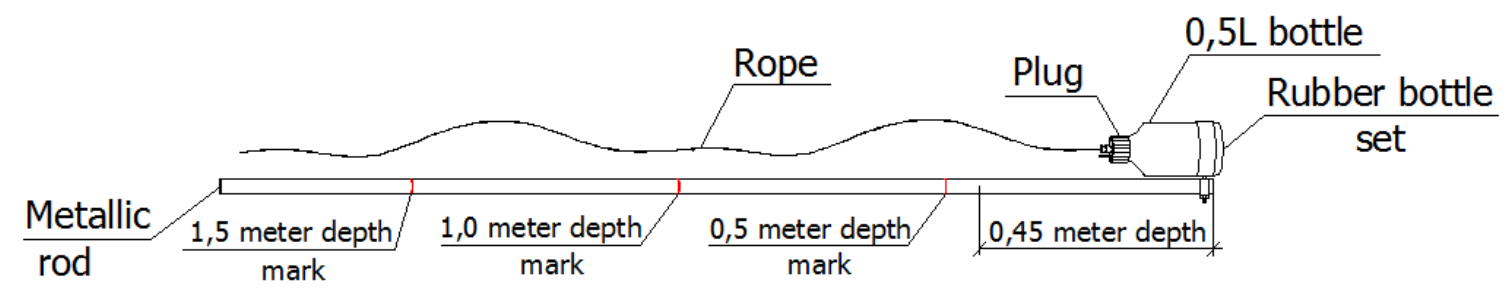

Figure 3. Bathometer used to take storm water runoff samples from the sedimentation tank.

The first stage of the experiment was devoted to clarify which sampling methodology should be used to determine the pollutant concentration in storm water runoff sedimentation tank: should it be the average of 8 grab sample, or is it enough to analyse one composite sample composed from 8 grab subsamples. Therefore each 1,5 litre volume grab sample was divided into two bottles: volumes of 1 litre and 0,5 litre. The concentrations of SS and TPH were determined in 1 litre sample whereas all 0,5 litre samples were mixed proportionally and one 1 litre volume composite sample was prepared for the determination of concentration of SS and TPH.

The initial pollutant concentration $\left(\mathrm{C}_{0}\right)$ for the estimation of removal efficiency of the first section was determined in grab samples taken at the inflow during all 5 researched rain events.

The construction of the outflow of the second section was improved, therefore samples were taken from three positions: 1) when treated storm water runoff flowed through overflow edge (0 cm depth); 2) when treated storm water runoff flowed through higher valve $(25 \mathrm{~cm} \mathrm{depth})$; 3 ) treated storm water runoff flowed from lower valve (45 cm depth), when general depth of water layer was $77 \mathrm{~cm}$ (Figure 2). The researched retention time was: 6 hours, 12 hours, 24 hours, 36 hours, 48 hours, 60 hours, 72 hours and 120 hours (5 days).

Treated storm water runoff was overflowing the edge only during the rain event and maximum 2 hours after it, therefore sampling at this point was much shorter and never exceeded duration of 2 hours. Later the level of storm water runoff in the sedimentation tank decreased and samples were taken only from valves. At the same time the first section discharge at the end of pipe was sampled as well. 


\section{Calculation or measurement of flow rate}

The storm water runoff inflow and outflow rate was calculated according the (2) formula when the depth of the water layer in a pipe is measured whereas diameter and slope of the pipe are known [5]:

$$
q=71,4 w R^{0,666-0,014 \sqrt{R}} \sqrt{i}
$$

here: $\mathrm{q}$ - flow rate, $\mathrm{m}^{3} / \mathrm{h} ; \mathrm{w}$ - wet perimeter of the pipe, $\mathrm{m}^{2} ; \mathrm{R}$ - radius of the pipe, $\mathrm{m} ; \mathrm{i}$ slope of the pipe, $\mathrm{m}$. The depth of storm water layer in the pipe was measured with a ruler.

The flow rate of two experimental valves was determined by volume method. The discharged water was filling certain size volume and the duration was recorded.

$q=\frac{V}{t}$

here: $\mathrm{q}$ - flow rate, $\mathrm{m}^{3} / \mathrm{h} ; \mathrm{V}$ - discharged water volume, $\mathrm{m}^{3} ; \mathrm{t}$ - duration of filling the volume, hours.

\section{Chemical analyses}

Storm water runoff was sampled between May 2009 and October 2009, according to [6]. Totally 131 grab sample was taken during 6 months. All analyses were done directly after the arrival to the laboratory, maximum 12 hours after the sampling. The transportation and storage were performed at $+4^{\circ} \mathrm{C}$ temperature. Samples were analysed according to Standard methods in the municipal laboratory of Vilnius "Grinda", certified by The Lithuanian Environmental Protection Agency. Chemical analyses were selected according to the requirements for the management of storm water runoff [7]. Storm water runoff was analysed for general parameters: suspended solids [8] and total petroleum hydrocarbons [9].

\section{RESULTS AND DISCUSSION}

The research of distribution of concentration of SS and total TPH in the sedimentation tank was performed at the second section only. The obtained results are shown in the Figure 4 and Figure 5. The average of SS concentrations of 8 grab samples did not varied very much from the value of composite sample during 5 researched rain events. The diapason of concentrations of SS was from $125 \mathrm{mg} / 1$ up to $345 \mathrm{mg} / 1$ (Figure 4 and Figure 5). The difference between grab sample values and value of composite sample was from $5 \%$ to $11 \%$. 


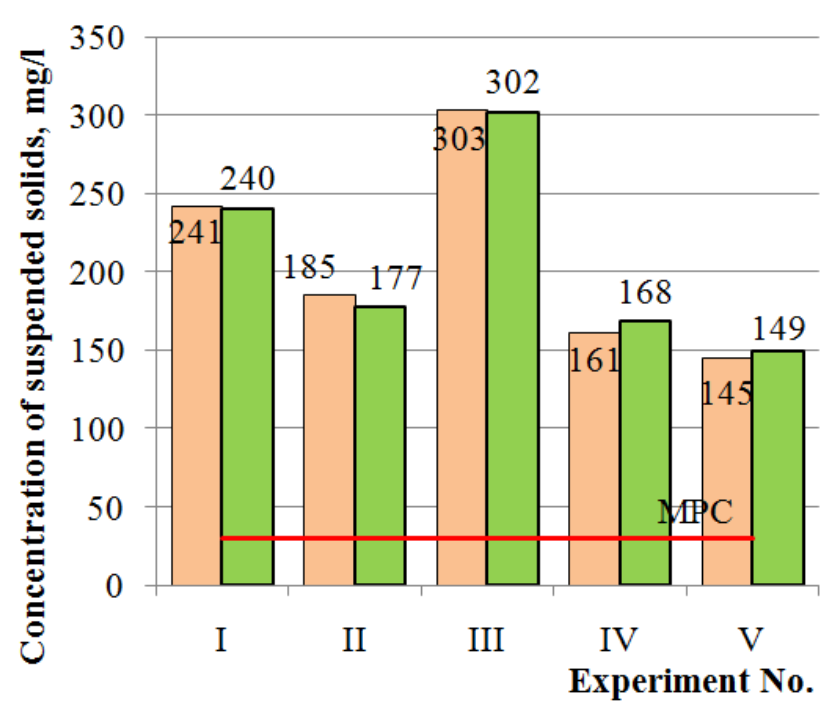

$\square$ Average concentration of SS of 8 grab samples, $\mathrm{mg} / 1$ $\square$ Concentration of $\mathrm{SS}$ in composite sample, mg/1 - MPC (SS), mg/1

Figure 4. The distribution of concentration of suspended solids in the sedimentation tank filled with a storm water runoff to capacity.

In general, accumulated storm water runoff in the sedimentation tank was unacceptably polluted, because determined values exceed the maximum permissible concentration (30 $\mathrm{mg} / \mathrm{l})$ from 4 up to 11 times.

The performed research of the distribution of TPH in sedimentation tank showed that concentrations determined in grab samples, which were taken from 8 different points of the sedimentation tank, were almost equal to the value of one composite sample, composed from 8 subsamples. The difference between composite sample value and values of grab samples ranged between $6 \%$ and $33 \%$. Determined concentrations of TPH were from 1,67 mg/l to $5,87 \mathrm{mg} / 1$ and in most cases didn't exceeded the maximums permissible concentration (5 $\mathrm{mg} / \mathrm{l})$.

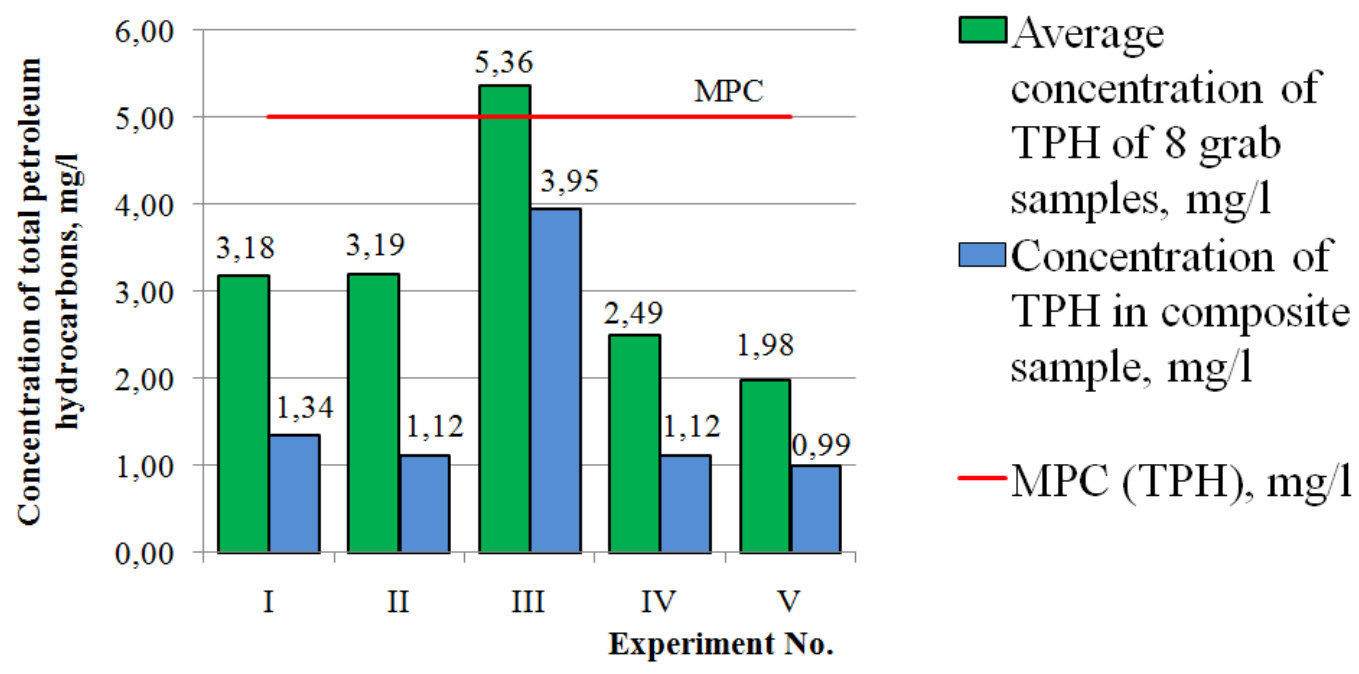

Figure 5. The distribution of concentration of total petroleum hydrocarbons in the sedimentation tank filled with a storm water runoff to capacity. 
The obtained results showed that the concentrations of SS and TPH were very similar all over the tank after a rain event. Therefore, it is more reasonable to take one composite sample instead several grab samples during the full scale research of sedimentation process efficiency.

Results from the experiments of removal efficiency indicate that average SS removal efficiencies ranged from 19\% to 94\% (Figure 6) and, for TPH, the removal efficiency ranged from $12 \%$ to $95 \%$ (Figure 7 ).

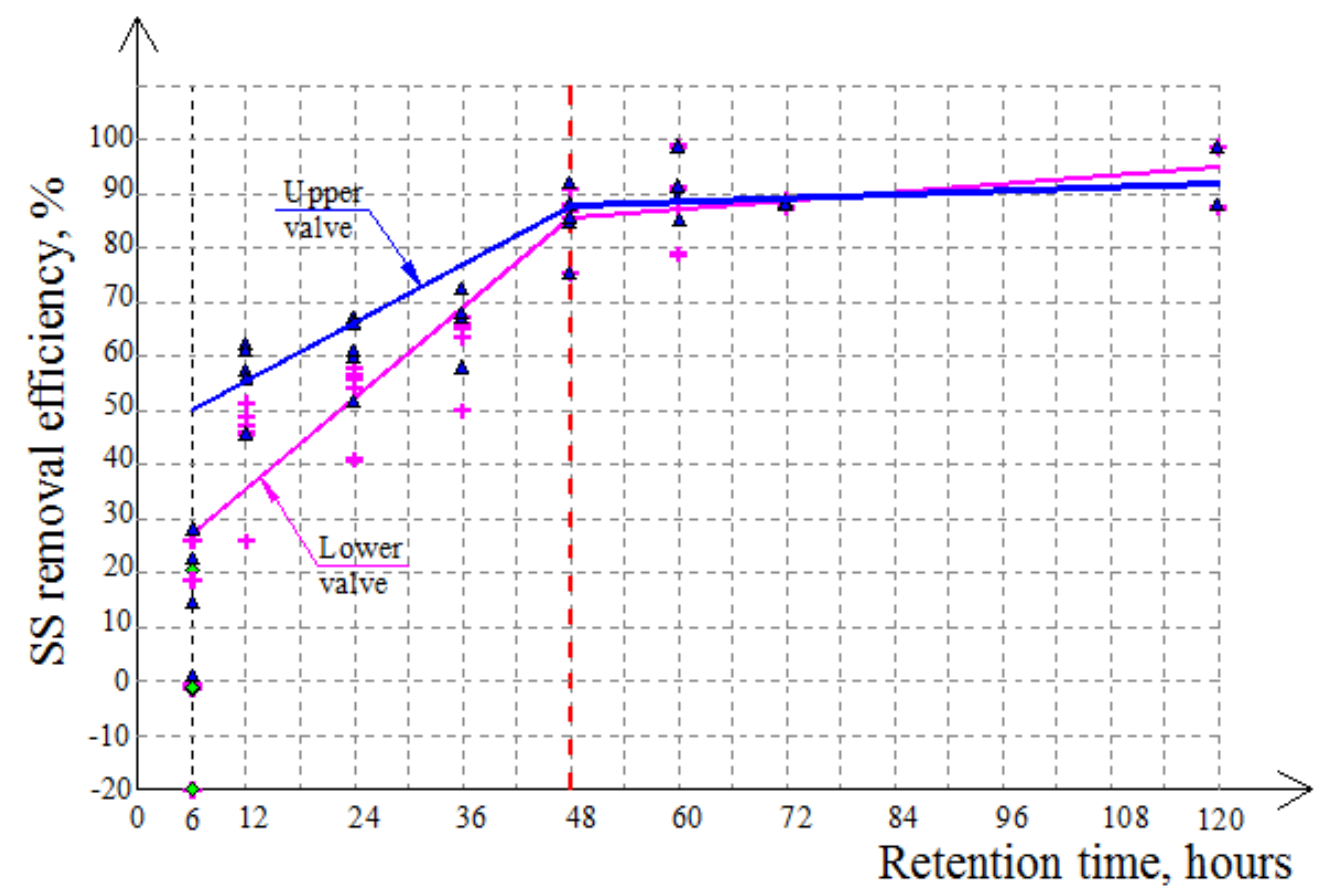

$\diamond$-SS removal efficiency during 5 experiments when storm water is disharged through overflow edge, $\%$

A-SS removal efficiency during 5 experiments when storm water is disharged through upper valve, $\%$

+-SS removal efficiency during 5 ex periments when storm water is disharged through lower valve, $\%$

-.---Recommended storm water retention time in sedimentation tank is 48 hours

-Average removal efficiency of SS when storm water runoff is disharged through upper valve

-Average removal efficiency of SS when storm water runoff is disharged through lower valve

Figure 6. The efficiency of the removal of suspended solids from storm water runoff accumulated in the second section of sedimentation tank.

The effectiveness of SS removal in storm water runoff sedimentation tank close to the upper valve reaches $60 \%$ already after 18 hours, $80 \%$ after 60 hours and $98 \%$ after 120 hours. At the same time, the effectiveness of SS removal close to the lower valve reaches $60 \%$ only after 36 hours, $80 \%$ after 67 hours and $98 \%$ after 92 hours.

In the second section, where the inflow was closed after the tank was filled with storm water runoff, the average concentration of SS decreased from $192 \mathrm{mg} / 1$ to $71 \mathrm{mg} / 1 \mathrm{after} 36$ hours and did not exceed maximum permissible concentration, which is $30 \mathrm{mg} / \mathrm{l}$, already after 48 hours. 
The effectiveness of TPH removal in storm water runoff sedimentation tank close to the upper valve reaches $60 \%$ after 36 hours, $80 \%$ after 51 hour and $98 \%$ after 66 hours. At the same time, the effectiveness of TPH removal close to the lower valve reaches $60 \%$ already after 16 hours, $80 \%$ after 62 hours and $98 \%$ after 96 hours. The effectiveness of TPH removal close the lower valve was higher, because of the TPH tendency to float.

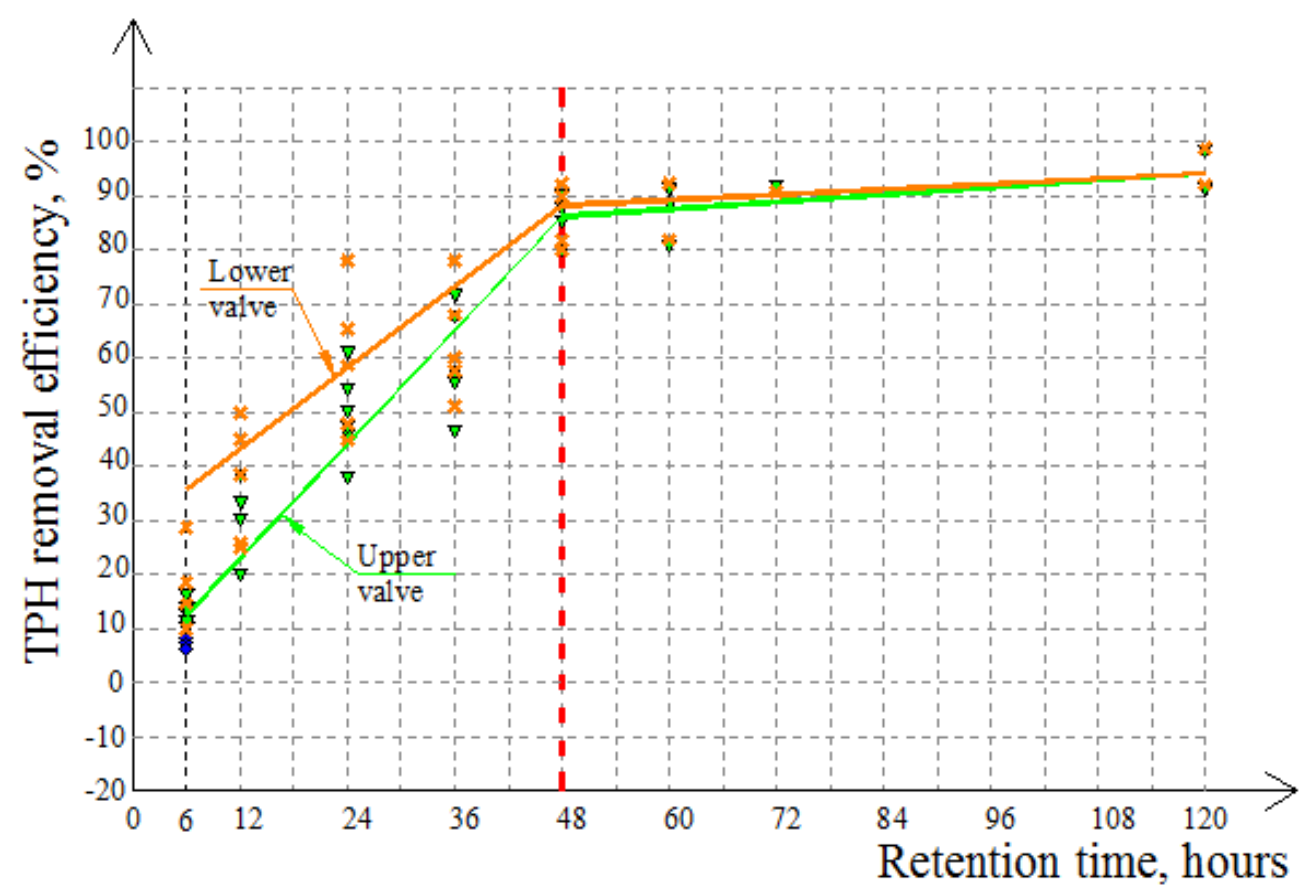

-TPH removal efficiency during 5 experiments when storm water is disharged through overflow edge, $\%$

$\nabla$-TPH removal efficiency during 5 experiments when storm water is disharged through upper valve, $\%$

x-PH removal efficiency during 5 experiments when storm water is disharged through lower valve, $\%$

-..--Recommended storm water retention time in sedimentation tank is 48 hours

-Average removal efficiency of TPH when storm water runoff is disharged through upper valve

-Average removal efficiency of TPH when storm water runoff is disharged through lower valve

Figure 7. The efficiency of the removal of total petroleum hydrocarbons from storm water runoff accumulated in the second sedimentation tank.

Actually, the optimal retention time is the most important for the proper operation of storm water runoff sedimentation tanks, because the discharged water should meet the environmental requirements and be as small as possible. Therefore the optimal retention time, actually, is the minimal retention time.

The performed research of outflow quality according the concentration of suspended solids and the concentration of total petroleum hydrocarbons from different depth indicated that optimal retention time for the accumulated storm water runoff at the researched sedimentation tank is 48 hour, when the inflow and outflow of sedimentation tank are closed necessarily. 
Also, it is important to mention that the experimentally determined retention time very well correspond with the knowledge presented in the literature [4].

During the investigation of dependency between storm water runoff retention time and treatment efficiency wide range of concentrations of SS and TPH was determined therefore the present operation set was evaluated. The researched first section of sedimentation tank worked inefficiently because of the inappropriate hydraulic regime. It was clearly seen from results obtained from samplings performed during rain events. Concentrations of SS and TPH determined in the first section outflow samples taken in the end of rain, or maximum 2 hours 